\title{
Man missing
}

\section{Towards a biography of Charles Brasch}

\section{SARAH V. QUIGLEY}

Someone else, I see,

Will be having the last word about me,

Friend, enemy, or lover

Or gimlet-eyed professor .... ${ }^{1}$

Having had the good fortune to gain one of the 1991 PENStout Fellowships, I was recently given an opportunity which is rare enough in the lifetime of any writer or researcher, let alone one in New Zealand - time to pursue a cherished literary ambition, and financial support to help realize this. While writing a thesis on the poetry of Charles Brasch a couple of years ago, perhaps inevitably I turned for a starting point to biographical fact. The attempt to seek in 'real life' detail some insight on the written word gradually led to a long-term plan to write some comprehensive biographical study of this poet and literary editor.

It seems appropriate here to look back nearly nine years to the inaugural conference of the Stout Research Centre in 1984, for the theme of this was, in fact, biography. One of the outcomes was Biography in New Zealand, the collection of essays first offered as papers at this conference. ${ }^{2}$ In his contribution, Antony Alpers outlines his belief that biography should be more than an examination of an individuallife:

James Bertram (left) with Charles Brasch, Rostov on Don, 1934.

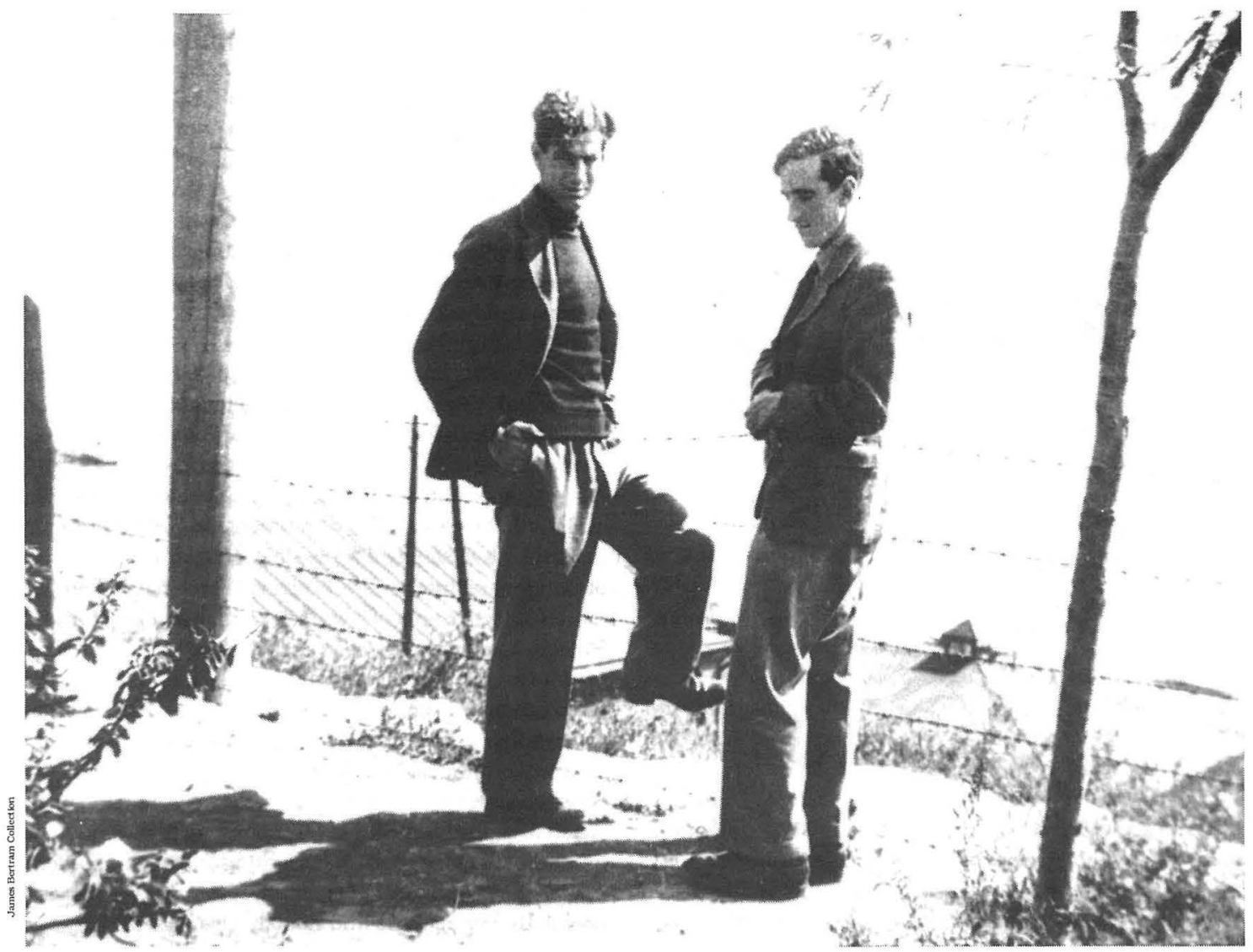

STOUT CENTRE REVIEW FEBRUARY 1992 
Nowadays, when I say the word 'biography', I no longer see a book, concerned with a person. I see a process, spread over decades at least, which leads eventually to the emergence of an historical view (of rather more than the person) and which is merely set in motion by the book that I have called the 'primary biography'.That book has to be followed by books from later writers who do not have to argue for the basic facts, but can take them as established ... ${ }^{3}$

The 'basic facts' of Brasch's life are, by this stage, fairly well known. In the field of post-war New Zealand literature he is a prominent figure, and an important one in the history of this country's culture. Although as a poet he has received less recognition than such contemporaries as Mason, Fairburn, and Glover, he attained a recognized standing in the literary world with his twenty-year-long editorship of Landfall, from its conception in 1947 onwards. Yet surprisingly little has been written about a man who edited New Zealand's first successful literary periodical, who was a generous patron and enthusiastic promoter of the arts, and who was a prolific writer in both poetry and criticism.

The only work to date approaching a biography of Brasch is a slim volume written for the New Zealand Writers series by James Bertram. ${ }^{4}$ A close friend of Brasch's since their school days together at Waitaki Boys', Bertram is obviously one of those best qualified for such an undertaking, and this work provides a comprehensive outline of major dates and events in Brasch's life. However, in keeping with the tone of the series, and doubtless partly because of the unavailability of primary sources, Bertram's Charles Brasch is more of a general assessment of the work of a poet and editor than a completebiographical 'investigation'. Undoubtedly there exists a need for some full scale biography, one which not only covers the public figure butalso the more private Brasch, and

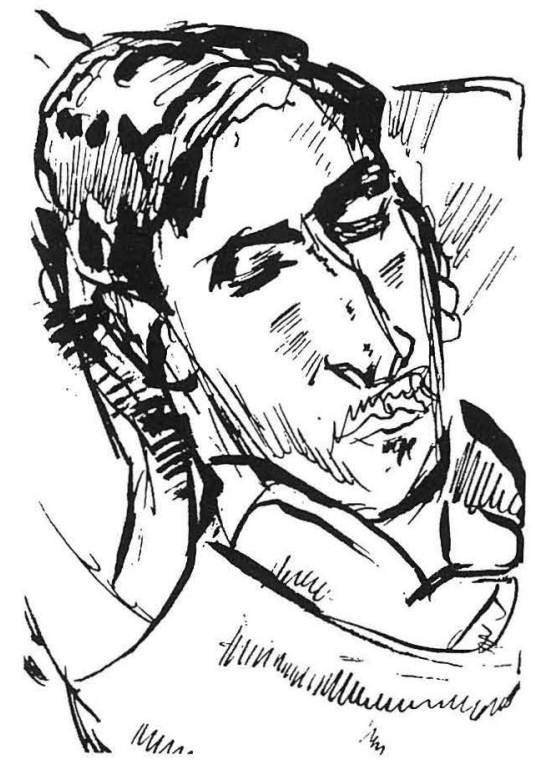

which reassesses both public and private aspects in relation to the general social and artistic climate of the time.

It is now nearly half a century since Brasch began his editorship; and the clarity of vision offered by hindsight, advantageous for any objective analysis, is perhaps still more so in a country such as this with a relatively short literary history. In recent decades there has been a tendency to view the Landfall generation, European and maledominated as it was, in a rather negative light: an inevitable reaction, perhaps, to the widely promoted reputation in the forties, fifties, and early sixties of these writers as the initiators of an established 'indigenous' culture. Possibly this, too, is one of the reasons why Charles Brasch (even more European-orientated than most of his contemporaries) has been somewhat neglected in the literature of the 1970 s and 1980s. I feel that it is time to place man and writings back in a 'realistic' perspective which is undistorted by the vagaries of literary vogue. Any attempt to write the 'primary biography' of Brasch, then, necessitates a reevaluation of literary society's attitudes past and present.

Such matters are, of course, problems inherent in the very genre of biographical writing. Yet as I progressed with my research I became increasingly aware that the difficulties encountered in such work are greatly magnified by the very nature of the man I am preparing to write about. In an interview with Ian Milner late in 1973, Brasch admitted: 'I often have the feeling that I don't exist personally except in the poems I write'. ${ }^{5}$ As an intensely private person, however, Brasch wrote many poems which are vividly descriptive landscape pieces; the poetry of his first two volumes, The Land and the People and Disputed Ground, in particular, focus on external detail to the exclusion of human content. Even the more subjective writing in the four succeeding volumes provide us with little revelation of the poet's identity. ${ }^{6}$ The love poetry in Ambulando (1964), for example, centres on an emotional and sexual relationship of the poet's, but it remains a carefully edited, concisely worded work, cryptic in its reticence; without recourse to primary sources (to which access is still restricted) we can only conjecture on the biographical reality behind the words.

I think there can be little argument that with any literary biography it is simply not possible to separate the aspects of exterior and interior life, of straightforward facts and the more subjective area of a writer's work. And I feel that with Brasch, more than most perhaps, an attempt to divorce work of art from artist is both unrealistic and unwise. Yet although he felt that his existence became most real in his poetry, this alone is not sufficient to provide us with a detailed outline of his personal development: his very consciousness of self prevents this. At one point in his autobiography he speaks of his attempt to find some sort of immovable 'centre', both in his writing and in his emotional life: 'It was to be my greatest difficulty to conceive and write poems that were mine and nobody else's, to find my own 
voice, live my own life....' ${ }^{7}$ Almost an entire section in his fifth volume, Not Far Off (1969), reflects this preoccupation with identity: the impossibility both of capturing it in words and, simply, of ever maintaining a constant identity from day to day. Brasch's acute sense of his own 'unfixed fluctuating identity', ${ }^{8}$ and his search for some enduring interpretation which would define himself in his own and others' eyes, was clearly not only a motivating force in his writing, but one of the essential parts of his very personality. In displaying this, his poetry provides a valuable insight into the mind of a very private man.

Yet it is a limited insight. The consciousness of self which pervades this poetry extends, naturally enough, to an acute consciousness of the reader, and so Brasch's honesty is only partial. His poetic art is one which is, without fail, meticulously crafted and carefully edited. Diverse in style, Brasch's poetry reflects the complexity of its creator. It shows a desire for close emotional union with others, but at the same time confirms Brasch's essential reserve and need for solitude:

To speak out is more desperate than to keep silence, To open the heart is to bleed to death surely. ${ }^{9}$

Thus his poetry seems to me to be an essential starting point for arriving at an understanding of the man behind the words; but it is no more than that - a starting point.

From what is at times frustratingly reticent poetry, I returned to those details of Brasch's life that he has made openly accessible to us: his autobiographical work entitled Indirections. A re-reading of these prose memoirs confirmed my impression of the paradoxical nature of the writer. Renowned (and, at times, criticized) for his meticulous approach as editor of Landfall, Brasch is no less methodical as autobiographer. Indirections is a comprehensive and detailed account of his life, from his earliest memories of Dunedin in the second decade of this century, to the death of his grandfather, Willi Fels, in 1946. Yet in this personal account the public image of a highly intelligent, assured and well-educated man is tempered by the impression of another Brasch: diffident, intensely private, and beset throughout his life with feelings of inadequacy. This is a fascinating work on this count alone, for it allows a reader some insight at least into the interior life of its author, particularly in the way that it exposes the uneasy relationship between Brasch and his father which undoubtedly had far-reaching effects on the emotional development of the former.

Like the poetry, however, there is a reticent quality about this autobiography, unexpected in a genre of an inherently personal nature, yet not entirely unexpected, perhaps, in the case of Brasch. In its adherence to concrete reality the

Opposite: Brasch at Mapua,1938. Ink sketch by Toss Woollaston, Hocken Library.

Above: Brasch in London. Pen and wash by Helen Kapp, Hocken Library.

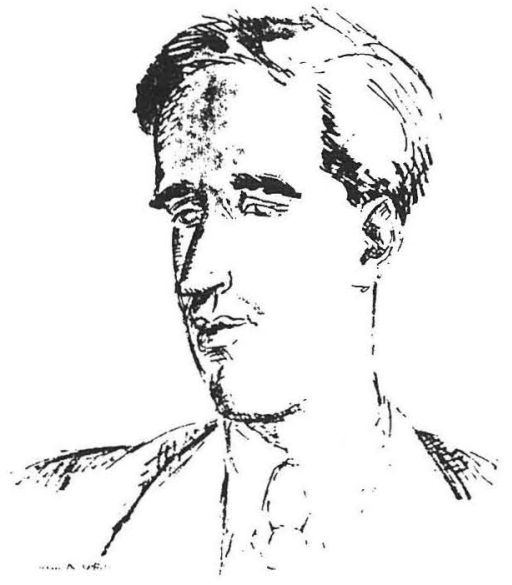

work is conscientiously detailed, keeping the reader fully informed of the developments in the writer's study, travels and career path. Yet in his interpretation of the self, Brasch is less scrupulous, less direct. Even when writing of intensely personal experiences (his first love affair at Oxford, for instance, or the death of his sister, Lesley), there is a sense that he is distancing himself from his own emotion and the reader is still further alienated from the original incident. I am sure that this reserve is partly deliberate. Brasch's lifelong vigilance against self-revelation manifests itself throughout Indirections, with the result that the work is a curious blend of intimacy and aloofness, invaluable to a researcher for its factual detail but offering limited and elusive 'human' content. Furthermore, these memoirs cover only the first forty or so years of Brasch's life; the years from 1947 until his death in 1973, during which he established Landfall and developed considerably as a poet, are not touched upon.

One of the huge advantages - and pleasures - of researching a New Zealand writer is the possibility of meeting those who knew the subject personally. Over his twenty years as editor of Landfall, Brasch built up a wide circle of friends and acquaintances, in literary, musical and artistic spheres, throughout both North and South Islands. In Wellington I was able to meet with some of those people who were willing to share their memories of Brasch, either as personal friends, or as literary associates, or both; James and Jean Bertram, and Margaret Scott (three of Brasch's closest friends), John M. Thomson, Janet Paul, and Maurice Gee all shared invaluable reminiscences with me. Despite the fact that all knew him in different capacities, Brasch now emerged for me as a far more cohesive figure, although no less of a paradox. For him, human friendship was obviously one of the most important touchstones in a transient world. (Many of his later poems are celebrations of human relationships and all that 
they entail.) All who knew Brasch well comment on the warmth, generosity, and commitment he brought to his personal relationships. Their private testimonies are publicly backed up by a page in the December issue of Landfall in 1966, Brasch's last year as editor; at the top is the inscription 'This page is to surprise and honour Charles Brasch', and more than eighty well known signatures follow - evidence enough of the liking and respect that most of his friends and colleagues had for him. ${ }^{10}$

Yet even those closest to Brasch speak of his unfailing formality of manner, and his reserve. To the end of his life he appears to have remained an essentially private person, and one to whom isolation was both an unwelcome part of existence and a salvation. At Brasch's funeral in May1973, Alan Horsman spoke of this characteristic reticence, giving the opinion that Brasch led a life 'the most intense parts of which were secret'. ${ }^{11}$ And in the Spring 1973 issue of Islands is a section dedicated to Brasch, which echoes this sentiment. Written by some of those who knew him bestthe de Beers, James Bertram, Jack Bennett, Toss Woollaston, Denis Glover, Douglas Lilburn, W.H. Oliver, Ian Milner these tributes reinforce the picture of a loyal and sensitive friend. One quality that is commented on once again is that curious blend of aloofness and generosity of spirit which characterized Brasch's friendships. Bill Oliver, for instance, writes of Brasch's 'carefully maintained reserve, his essential privacy and solitude'. Lilburn remembers being 'disconcerted by his reserve, veiling warmth of personality', and states: 'Whole areas of his life and thought remained sealed books to me throughout a long friendship.' ${ }^{12}$

Many parts of Charles Brasch's life will remain 'sealed books', not only to his friends but to the general public at least until his journals and letters are released in 2003. Brasch seems to have respected the privacy of others as much as his own, for before his death he placed a thirty-year embargo on his personal papers. Margaret Scott informed me that Brasch wrote detailed diaries throughout most of his lifetime; ${ }^{13}$ these records of his innermost thoughts now lie unopened in Dunedin's Hocken Library. Some of his own letters to others, such as Frank Sargeson and Ursula Bethell, are available for restricted public access in various collections throughout New Zealand; the content of these is, however, largely of literary matters and the tone unfailingly calm, considered, revealing little about Brasch's personal life or emotional state of mind.

From the few details of Brasch's life that he has chosen to make accessible to us, we may begin to grasp the complexity, and contradictions, of his nature: a man of high intelligence yet surprisingly diffident about his own abilities, loyal and even passionate in his personal associations yet maintaining always that barrier of reserve. Such biographical detail combined with continued close readings of his poetry brings me gradually closer to an understanding of the many sides of Brasch. Yet I am now convinced that attempts to draw definitive conclusions about his work or himself before the release of his most personal writings can only result in possibly inaccurate interpretations or halftruths.

In a poem entitled 'Man Missing', Brasch himself, with his unfailing awareness of the contradictions of his own personality wryly acknowledges the difficulty of building up a comprehensive picture of himself:

Analyse and prod me

As I will, as they will,

Nothing quite fits the bill;

And the man writing this now

Is gone as he makes his bow. ${ }^{14}$

And so I am prepared to wait another eleven years before attempting that 'primary biography' which Alpers speaks of: '... biography which is able to make the first complete examination, under suitable conditions, of all known documents ... ${ }^{15}$ Perhaps then, with recourse to Brasch's own thoughts on himself and his relationships with others, I can hope to achieve some 'truthful' interpretation, as far as this is possible in any biographical work; an interpretation not just of the established public image of editor and poet, but of another, more private, Brasch.

My thanks go to all those at the Stout Research Centre, and elsewhere, who assisted me in my research during my time in Wellington. I would appreciate hearing from anyone who has further information on, or personal memories of. Brasch; I can be contacted c/o the English Department, University of Auckland.

\section{Footnotes}

${ }^{1}$ Charles Brasch, 'Man Missing', Collected Poems (Auckland: Oxford University Press, 1984), p.135.

${ }^{2}$ Ed. Jock Phillips (Wellington: Allen \& Unwin/Port Nicholson Press, 1985).

${ }^{3}$ 'Literary Biography (in New Zealand)', Biography in New Zealand , pp.19-29.

${ }^{4}$ Charles Brasch (Wellington: Oxford University Press, 1976).

5Ian Milner, 'Conversation with Charles Brasch', Landfall 100, vol.25, no.4, December $1971 ;$ pp.344-372

${ }^{6}$ The Estate (Christchurch: Caxton Press, 1957); Ambulando (Christchurch: Caxton Press, 1964); Not Far Off (Christchurch: Caxton Press, 1969); Home Ground (Christchurch: Caxton Press, 1974).

7 Indirections: A Memoir 1909-1947 (Wellington: Oxford University Press, 1980), p.192. Indirections, p.368.

'Open the Heart', Collected Poems, p.137.

${ }^{10}$ Landfall 80, vol.20, no.4, December 1966. In a letter to Frank Sargeson, dated 11 December, 1966, Brasch speaks of this tribute with rare emotion and typical modesty: The page of signatures in Landfall is delightful and made me laugh for pleasure.... feel grateful to everybody, to you above all.... All very intriguing and I smile again and again over it.' (Sargeson Collection, Ms. Papers 432, Folder 149, Alexander Turnbull Library, Wellington.)

11 'Words at the Funeral of Charles Brasch', Islands, O.S.2(1973), p.230

${ }_{12}$ 'Tributes and Memories from his Friends', Islands, O.S.2, (1973), pp.233-251; these quotations p. 247 and p.250.

${ }^{13}$ Interview with Margaret Scott, 26 November 1991, Wellington.

14 'Man Missing', Collected Poems , p.135.

${ }^{15}$ Biography in New Zealand, p.27.

Originally from Christchurch., Sarah Quigley gained an M.A. from the University of Canterbury in 1990. Her thes is focused on the dual influences of landscape and visual art on the poetry of Charles Brasch. She is now tutoring in New Zealand literature at the University of Auckland, and in the near future intends to commence research for a Ph.D. centred around the publishing house of Faber and Faber. 